УДК 52-526

\title{
Структура вторичных конгломератов, образовавшихся при воздействии лазерного излучения на желчные камни
}

\author{
О.В. Андрухова ${ }^{1}$ Т.В. Андрухова ${ }^{2}$ А.Ю. Филимонова \\ ${ }^{1}$ Алтайский государственный технический университет им. И.И. Ползунова \\ (Барнаул, Россия) \\ ${ }^{2}$ Алтайский государственный университет (Барнаул, Россия) \\ ${ }^{3}$ Средняя общеобразовательная школа № 70 (Барнаул, Россия)
}

\section{The Structure of Secondary Conglomerates Formed due to Exposure of Gallstones to Laser Radiation}

\author{
O.V. Andrukhova $a^{1}$ T.V. Andrukhova ${ }^{2}$, A.Yu. Filimonova ${ }^{3}$ \\ ${ }^{1}$ Polzunov Altai State Technical University (Barnaul, Russia) \\ ${ }^{2}$ Altai State University (Barnaul, Russia) \\ ${ }^{3}$ Comprehensive secondary school № 70 (Barnaul, Russia)
}

\begin{abstract}
Проведен анализ особенностей строения и элементного состава желчных камней в зависимости от их типа. Элементный состав камней был исследован методом рентгенофлуоресцентного анализа, структурное строение до и после воздействия лазерного излучения - методом микроскопии. В элементный состав желчных камней всех типов входят микроэлементы: железо, хром, никель, медь, марганец и сера. Содержание микроэлементов в ядре и поверхностных слоях желчных камней зависит от типа камня. Проведено исследование структуры шлифов желчных камней различного состава до и после воздействия лазерного излучения и структуры кристаллических образований на их поверхности в зависимости от времени воздействия. Показано, что механизм разрушения различен для разных структурных элементов желчных камней. Рассчитана фрактальная размерность объектов, образовавшихся на поверхности шлифов после воздействия лазерного излучения. Анализ морфологической картины структурных изменений поверхности биоминеральных образований после воздействия лазерного излучения включал определение следующих структурных параметров: целостность контуров зоны облучения, наличие структурных разрушений и их характер.

Ключевые слова: патогенные органоминеральные образования - конкременты (желчные камни), микротвердость, элементный состав, рентгенофлуоресцентный анализ, фрактальная размерность.
\end{abstract}

DOI 10.14258/izvasu(2019)4-02
The paper analyzes the features of structures and elemental compositions of gallstones depending on their types. Elemental compositions of gallstones were studied by x-ray fluorescence analysis, while their structures before and after exposure to laser radiation were studied by microscopy. The elemental compositions of all types of gallstones include the following trace elements: iron, chromium, nickel, copper, manganese, and sulfur. The combination of trace elements in the core and surface layers of gallstones depends on the type of gallstone. Section structures of gallstones of different elemental compositions before and after exposure to laser radiation and the structure of crystalline formations on their surface in relation to the time of exposure are studied in this paper. It is shown that the mechanism of destruction varies for different structural elements of gallstones. The fractal dimension of the objects formed on the surface of the sections after exposure to laser radiation is calculated. The analysis of the morphological pattern of structural changes in the surface of biomineral formations after exposure to laser radiation includes the determination of the following structural parameters: the integrity of the irradiation zone contours, the presence of structural damages and their nature.

Key words: pathogenic organomineral formations - concretions (gallstones); microhardness; elemental composition, $\mathrm{x}$-ray fluorescence analysis; fractal dimension. 


\section{Введение}

Накопление патогенных органоминеральных образований (конкрементов) происходит вследствие застойных процессов в желчном пузыре. Удаление патогенных органоминеральных образований из желчного пузыря лазером - одна из прогрессивных медицинских методик, позволяющая раздробить желчные конкременты и вывести их из организма, сохранив орган и его функции $[1,2]$.

Прицельная контактная лазерная литотрипсия осуществляется при использовании устройства для фиксации камней, при этом повышается эффективность фрагментации конкрементов. С целью гарантии безопасности литотрипсии и уменьшения рецидивов необходим анализ изменений структуры желчных камней и образовывающихся вторичных структур на всех этапах процесса воздействия лазерного излучения (нагрев, плавление, фрагментация, обугливание, абляция, разрушение и др.).

Исследования изменений физико-механических характеристик патогенных органоминеральных образований (желчных камней), вторичных структур и процессов, происходящих при воздействии лазерного излучения, с помощью оптической микроскопии будут способствовать улучшению результатов лечения желчекаменной болезни.

Методика экспериментов и результаты исследований

В качестве объектов исследований были выбраны два вида желчных камней с разными морфологическими особенностями. Было исследовано 10 образцов желчных камней, полученных при холецистэктомии, проведенной в хирургическом отделении КГБУЗ «Городская больница № 5» г. Барнаула в первом квартале 2016 г.

Для выявления особенностей структуры конкрементов и последующих исследований были изготовлены шлифы желчных камней. Желчный камень помещался в пластичный эпоксидный двухкомпонентный состав, после затвердевания его шлифовали и полировали. Образцы помещались в боксы и хранились в темном прохладном месте.

Во время исследования структуры шлифов выделялись следующие элементы: ядро, оболочка - для всех камней; слои, лучи - для камней с периодическим строением; поры, аморфные включения - для ряда камней с изотропным строением [3-7].

Первый образец (рис. 1) представляет собой конкремент, относящийся к типу слоистых камней. Шлиф желчного камня имеет периодически концентрическое строение, между ядром камня и его оболочкой располагаются концентрические зональности. Два сближенных центра срастания объединены в общую зону, что обусловлено слиянием отдельных агрегатов. Исследование поверхности этого образца методами микроскопии позволило выявить особенности строения слоистого потогенного органоминерального образования.

Микротвердость зоны ядра довольно низка (можно полагать, что зародышем камня является конкремент органического происхождения, отличающийся низкой твердостью), при движении к поверхности она немонотонно возрастает и возле поверхности снова уменьшается. Наблюдается значительный разброс значений микротвердости для различных участков шлифа: от значений $\mathrm{HV}=24 \div 28 \mathrm{H} / \mathrm{Mм}^{2}$ для области возле оболочки и в ядре и до $\mathrm{HV}=40 \div 65 \mathrm{H} / \mathrm{Mм}^{2}$ для слоев, окружающих ядро. Чередование областей со значительным разбросом HV связано с образованием слоев как органического происхождения, так и слоев преимущественно минерального состава (возможно, связанных также с кристаллизацией органических компонент). Средние значения микротвердости для основных зон камня составляют: для ядра $\overline{H V}=25 \pm 1 \mathrm{H} / \mathrm{MM}^{2}$, для оболочки $\overline{H V}=26,5 \pm 1 H / \mathcal{M M}^{2}$, для промежуточных зон $\overline{H V}=43,8 \pm 1 \mathrm{H} / \mathrm{MM}^{2}$. После воздействия лазерного излучения средние значения микротвердости для основных зон камня составили $\overline{H V}=81,7 \pm 8,45 \mathrm{H} /$ мм $^{2}$.

Второй образец (рис. 2) имеет радиально-лучистое строение. Радиально-лучистая структура обусловлена разрастанием кристаллов призматической формы (чаще всего холестерина) от центра перпендикулярно к поверхности камня. Ширина периферической части, отличающейся по цвету от центральной части образца, имеет практически одинаковую толщину по всей области шлифа камня, что свидетельствует о равномерном росте камня во всех направлениях. Поверхность радиально-лучистого желчного камня имеет однородное строение, ярко выраженные концентрические зональности отсутствуют, структура шлифа выглядит однородной, без выявленного ядра или оболочки.

Для большей части шлифа радиально-лучистого камня величина HV изменялась в достаточно узком интервале: от 35 до 50 H/Mм². Значения HV больше, чем у слоистого желчного камня. Скачки микротвердости в меньшую или большую сторону наблюдаются лишь в приграничной части оболочки. Средние значения микротвердости для основных зон камня составляют: для ядра $\overline{H V}=44,2 \pm 1,10 \mathrm{H} / \mathcal{M M}^{2}$, для оболочки $\overline{H V}=42,5 \pm 1,2 H / \mathcal{M M}^{2}$. После воздействия лазерного излучения средние значения микротвердости для основных зон камня составили $\overline{H V}=34,90 \pm 1,0 \mathrm{H} / \mathrm{MM}^{2}$.

Для исследования элементного состава патогенных органоминеральных образований $[8 ; 9 ; 10$, c. 506-514; 11, с. G38-G47] использовался рентгенофлуоресцентный анализатор Х-Арт М. Анализ спектрограммы радиально-лучистого желчного камня выявил в его составе железо (до 50\%), хром (15,7\%), кальций $(23,6 \%)$, никель (4,9\%), медь (0,5\%), марганец $(3,3 \%)$ и серу $(4,6 \%)$. Анализ элементного состава слоистого 


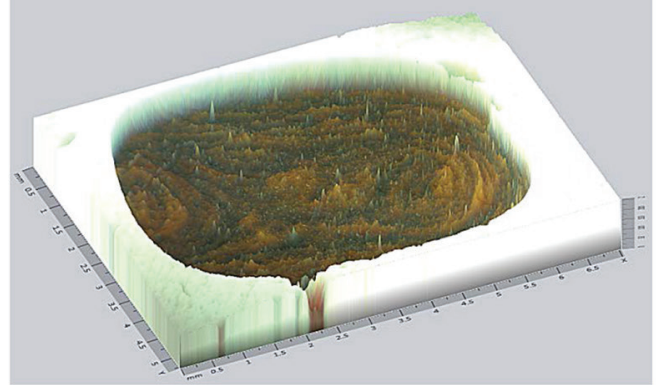

a)

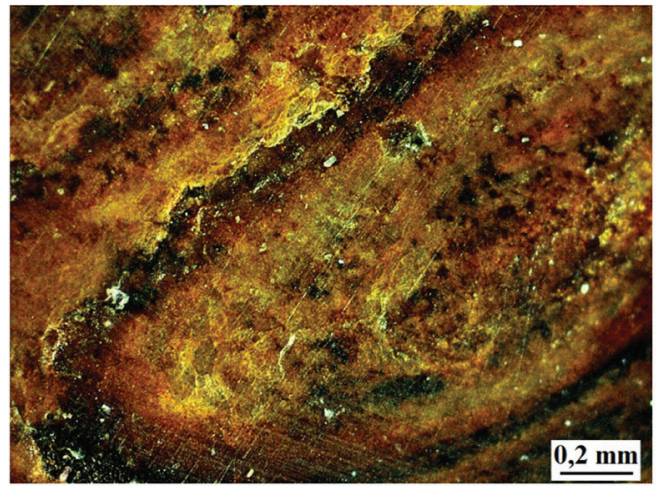

B)

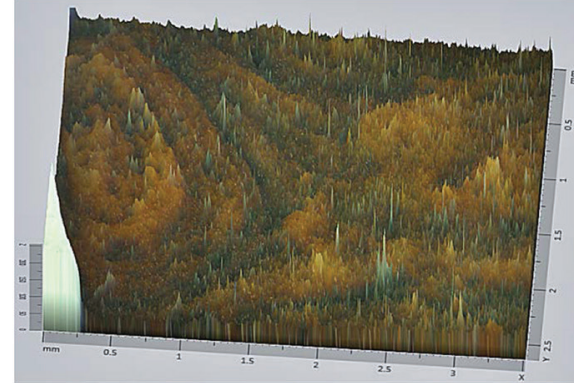

б)

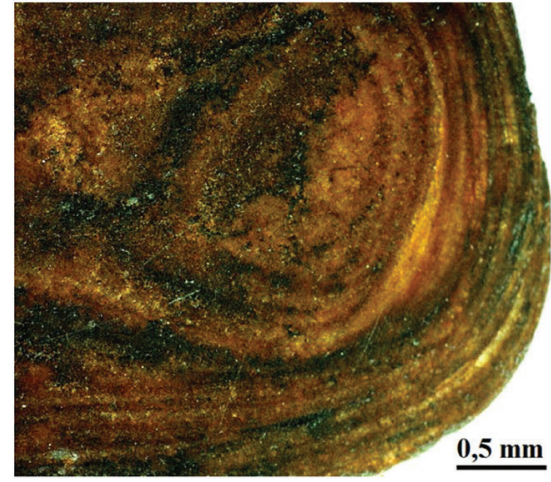

г)

Рис. 1. Шлиф слоистого желчного камня: а) сечение через центр образца (2,5D реконструкция); б) левое ядро образца (2,5D реконструкция); в) центральная часть образца; г) периферическая часть образца

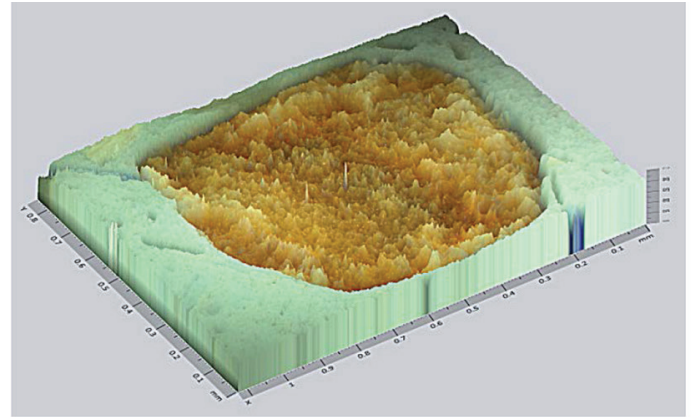

a)

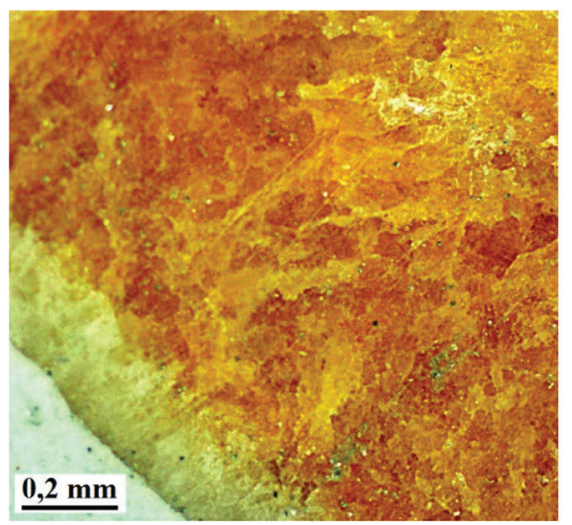

б)
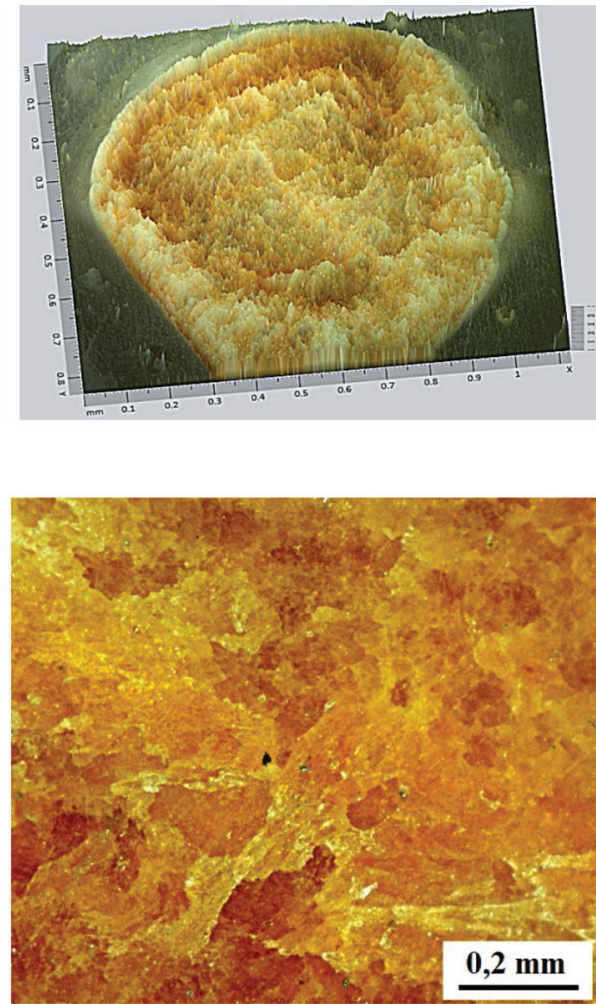

B)

Рис. 2. Шлиф радиально-лучистого желчного камня: а) сечение через центр образца (2,5D реконструкция); б) периферическая часть образца; в) центральная часть образца 
желчного камня показал содержание железа $(41,9 \%)$, хрома $(15,3 \%)$ и кальция $(31,1 \%)$, никеля $(3,6 \%)$, меди $(0,7 \%)$, марганца $(3,4 \%)$ и серы $(3,9 \%)$.

Поверхность шлифов желчных камней исследовалась с помощью метода оптической микроскопии на стереоскопическом микроскопе Stemi 2000-С с цифровой фото/видео системой. Программное обеспечение для получения и обработки изображений позволяет обрабатывать и анализировать изображения, проводить измерение высоты и шероховатости в 2,5-3D топографии. Изображения с 2,5D реконструкцией выполнены в пересчете $4 \cdot 10^{-4} \mathrm{~mm} / \mathrm{px}$.

На рисунках 1 и 2 представлены шлифы желчных камней до воздействия лазерного излучения.

При воздействия лазерного излучения на слоистый желчный камень вследствие анизотропии теплопроводности область воздействия имеет несимметричную форму. Время лазерного излучения составляло 45-360 с. При значительном времени воздействия лазерного излучения на желчный камень (рис. 3 a, б) фиксируется нарастание нитевидных кристаллов, уникальную форму которых можно сравнить с ватой, мехом или войлоком. При росте нитевидных кристаллов существенную роль играют винтовые дислокации, по которым и происходит преимущественный рост кристалла [12, с. 112-119; 13]. Волокнистые и волосовидные формы нитевидных кристаллов при воздействии лазерного излучения длиной волны в диапазоне 405-750 нм и интенсивностью $1,5 \cdot 10^{6}-5,3 \cdot 10^{6}$ Вт/ ${ }^{2}$ характерны для конкрементов со слоистой структурой и несоразмерными элементами отдельных слоев, что приводит к скручиванию их в тончайшие трубки. Внешне такие трубки выглядят как типичные нитевидные кристаллы, хотя их и следовало бы выделять в отдельный таксон трубчатых (цилиндрических) кристаллов.

При времени воздействия более 60 секунд (рис. 3 в) нитевидные кристаллы отсутствуют, и фиксируется наличие кристаллов игольчатой формы. При этом большая часть кристаллов расположена в центральной части области воздействия.

Если время воздействия 120 секунд и более (рис. 4 г), происходит выгорание органического вещества в центральной части образца, целостность кристаллической структуры нарушается и наблюдается увеличение роста неорганических кристаллов по периферии области воздействия лазерного излучения, при этом структура кристаллов разрастается в направлении, перпендикулярном шлифу образца.

В отличие от слоистого желчного камня, у радиально-лучистого желчного камня (рис. 4 а) при воздействии лазерного излучения длиной волны в диапазоне $405-750$ нм и интенсивностью $1,5 \cdot 10^{6}-5,3 \cdot 10^{6} \mathrm{BT} / \mathrm{M}^{2}$ первоначально отсутствует процесс разрушения, а происходит только частичное плавление. Задержка между началом воздействия лазерного излучения и момен- том появления разрушения структуры объясняется тем, что часть энергии затрачивается на разогрев мишени до температуры, при которой начинается испарение вещества.

При увеличении времени воздействия (рис. 4 б) зона плавления увеличивается, меняется цвет, и появляются игольчатые кристаллы по периферии зоны облучения, которые имеют вытянуто-ориентированную форму.

Под воздействием лазерного излучения на образец более 3 минут образуются нитевидные кристаллы спиральной формы (рис. 4 в, г). Этот процесс связан с тем, что при быстром нагревании материала фронт кипения догоняет фронт плавления и далее вся энергия излучения идет на испарение материала. Это происходит, когда плотность мощности излучения становится больше пороговой.

В результате воздействия $\mathrm{CO}_{2}$-лазера $\lambda=1060 \mathrm{Hм}$, $I=44 \cdot 10^{6} \mathrm{~B}$ T $/ \mathrm{M}^{2}$ на органоминеральные конкременты зафиксированы следующие результаты:

1. При времени воздействия $~ 3$ с у радиальнолучистого желчного камня происходит расслоение кристаллической структуры, выделяются отдельные кристаллы, которые можно увидеть невооруженным глазом, плавление остается неизменным, разрушения и выгорания не происходит, отсутствует рост нитевидных кристаллов. При увеличении времени воздействия до 12 с наблюдаются разрушение кристаллической структуры и плавление и испарение центральной части (область воздействия лазерного пучка), расслоение поверхности и плавление некоторой части радиально-лучистого желчного камня; т.е. эти процессы отмечаются при заданной мощности для любого времени воздействия.

2. При воздействии лазерного излучения $\mathrm{CO}_{2}$-лазером на слоистый желчный камень процессы на поверхности образца носят характер, аналогичный воздействию полупроводниковым лазером, но скорость протекания описанных выше процессов резко увеличивается. Так, при времени воздействии 3 с целостность кристаллической структуры нарушается, происходит полное выгорание органического вещества в центральной части и роста кристаллов не наблюдается. После воздействия в течение 12 с происходит полное выгорание органического вещества в центральной части; рост кристаллов, состоящих из неорганического вещества, идет по периферии; при этом структура кристаллов не разрастается вверх, а покрывается нитевидными кристаллами; в центральной части зоны воздействия происходит процесс обугливания и наблюдается формирование спекл-структур.

С помощью метода фрактальной размерности можно оценить шероховатость поверхности шлифа желчного камня до и после воздействия лазерного излучения, независимо от формы ее элементов 

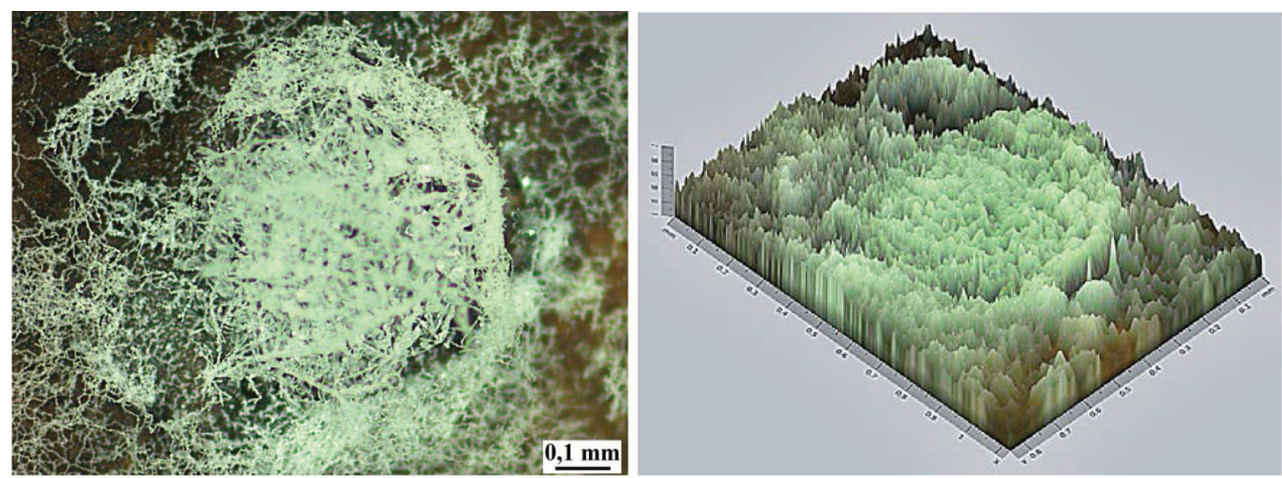

a)
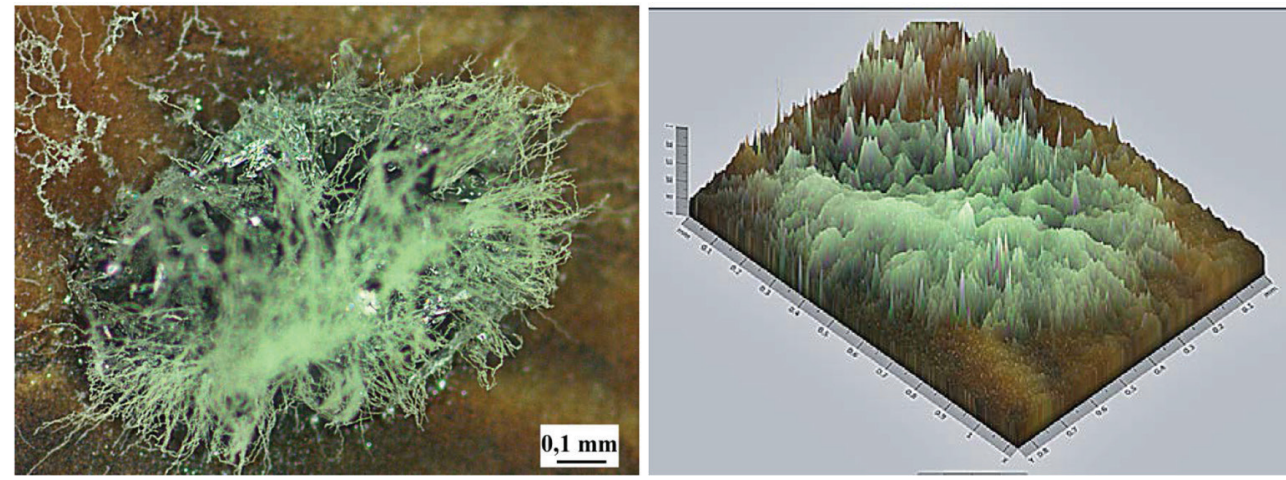

б)
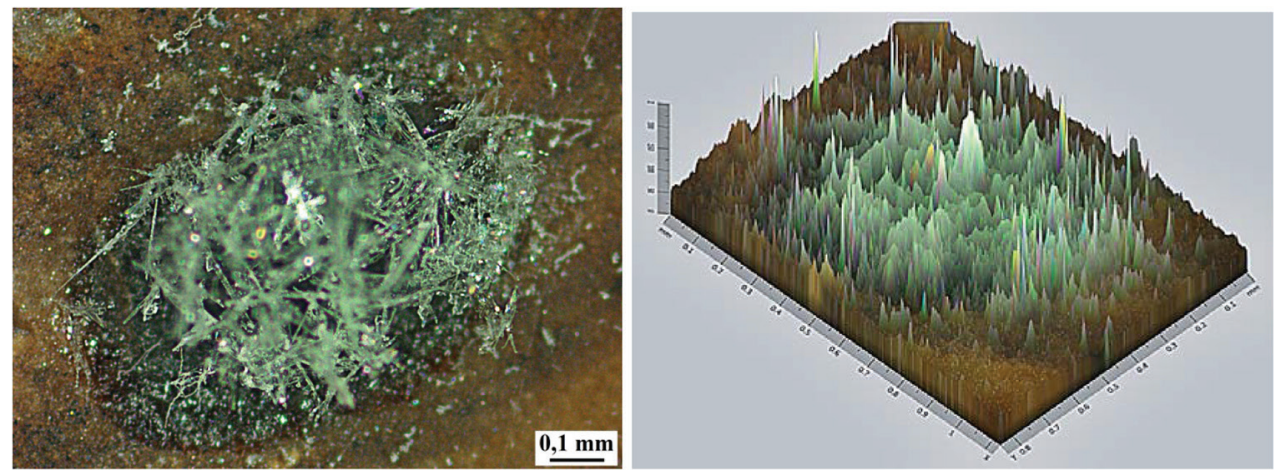

B)
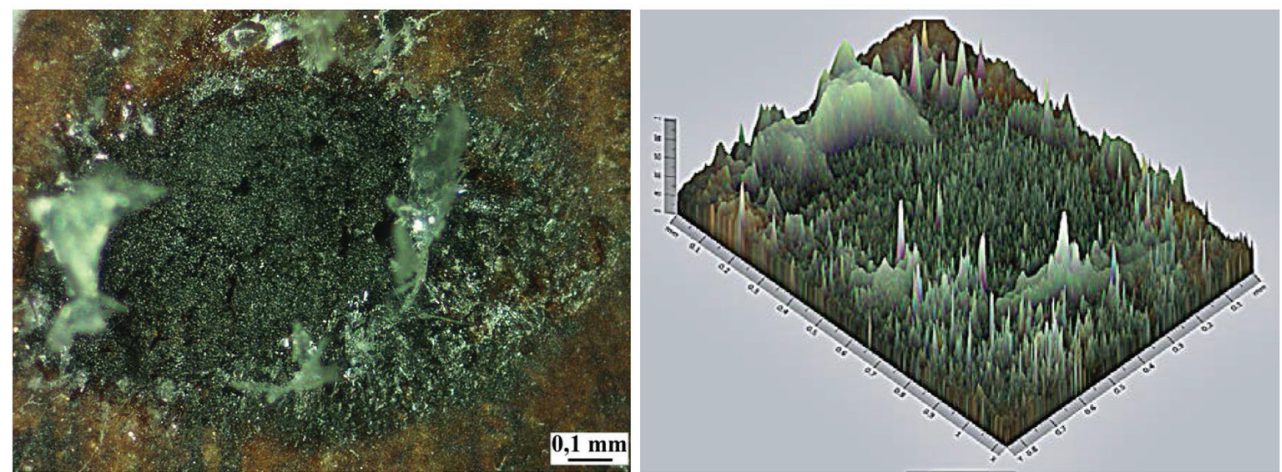

г)

Рис. 3. Область воздействия лазерного излучения $\lambda=405$ нм, $\mathrm{I}=2,55 \cdot 10^{6} \mathrm{~B}$ т/ $\mathrm{M}^{2}$ на слоистый желчный камень c $2.5 \mathrm{D}$ реконструкцией: a) $\mathrm{t}=60 \mathrm{c}$; б) $\mathrm{t}=75 \mathrm{c}$; в) $\mathrm{t}=90 \mathrm{c}$; г) $\mathrm{t}=360 \mathrm{c}$ 

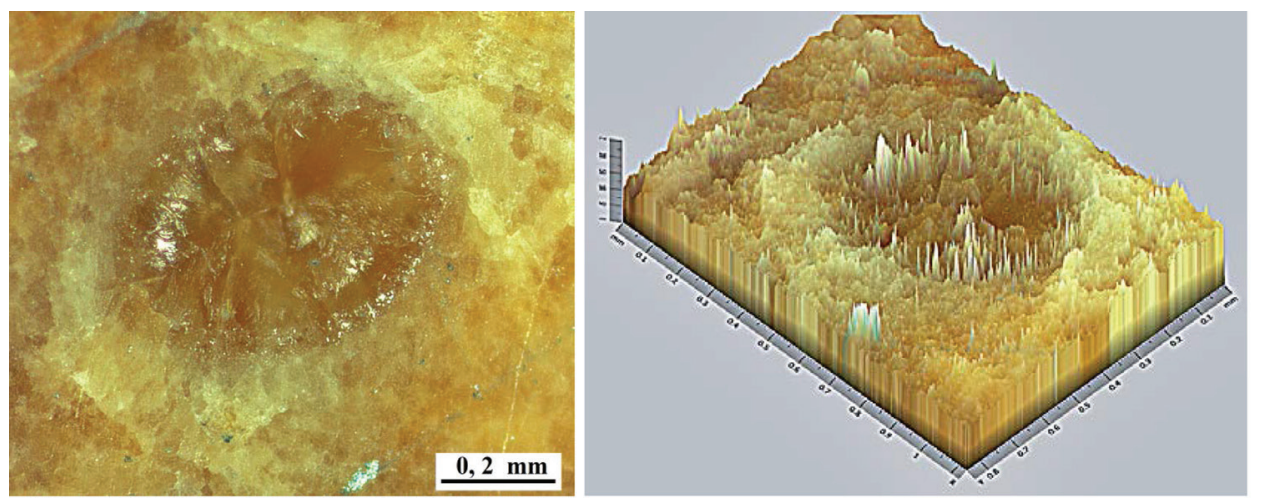

a)
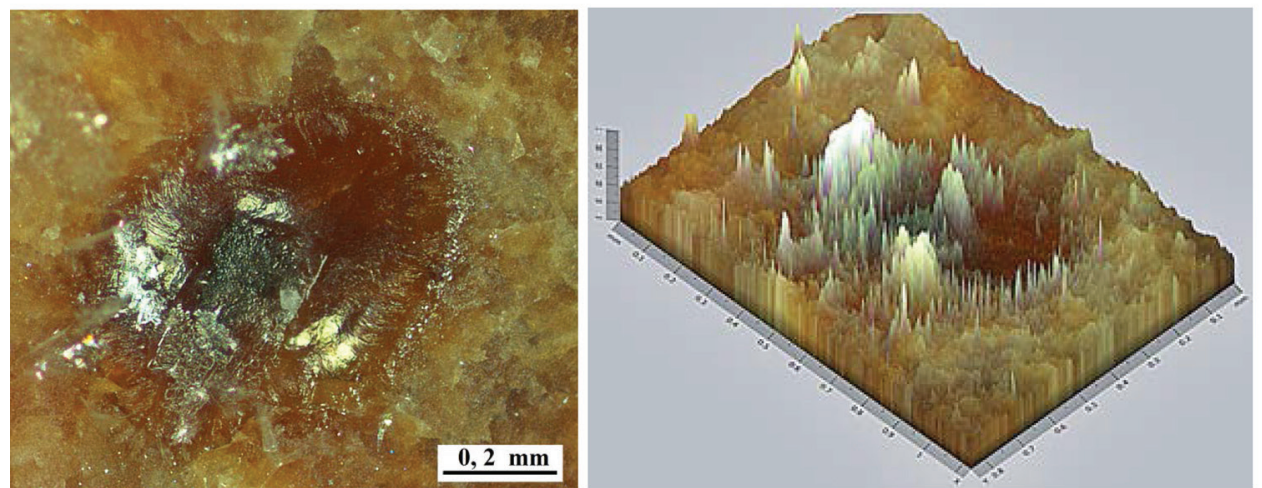

б)
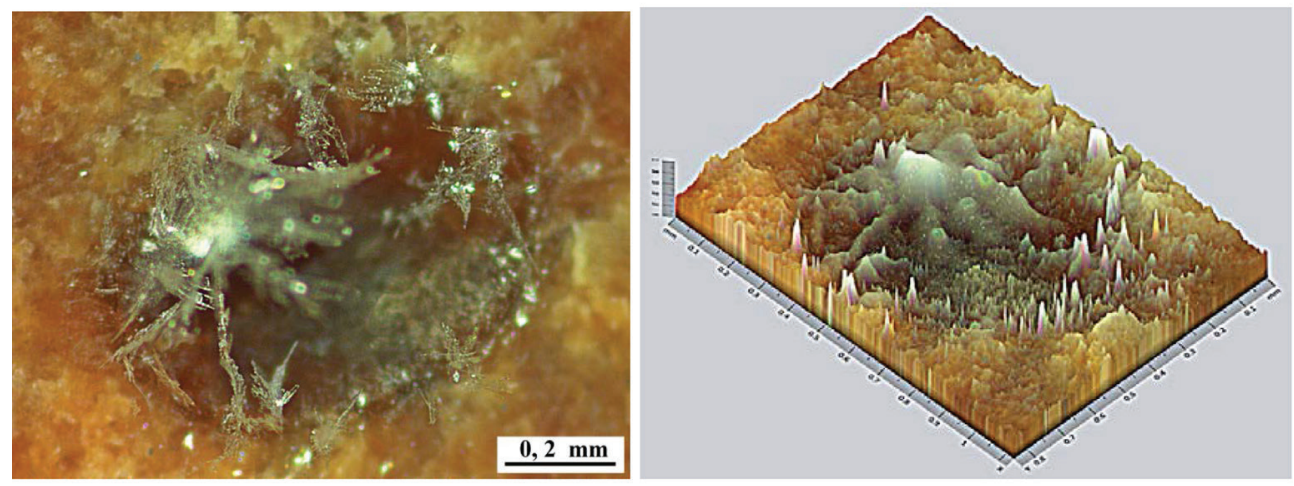

B)
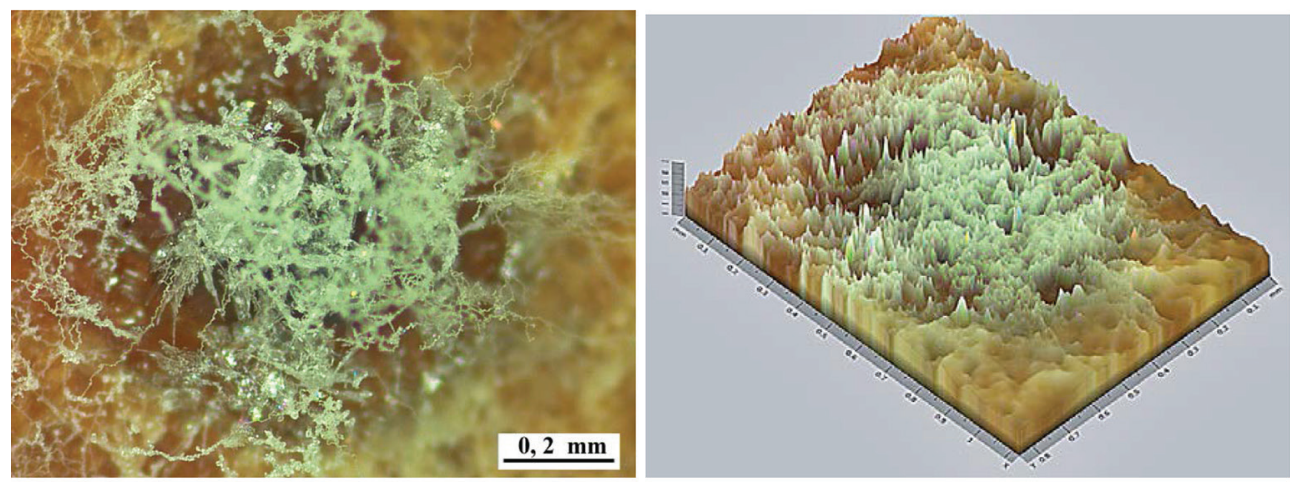

г)

Рис. 4. Область воздействия лазерного излучения $\lambda=405$ нм, I $=2,55 \cdot 10^{6} \mathrm{~B}$ т/ $\mathrm{M}^{2}$ на радиально-лучистый желчный камень с 2.5D реконструкцией: a) $\mathrm{t}=45 \mathrm{c}$; б) $\mathrm{t}=60 \mathrm{c}$ в в) $\mathrm{t}=75 \mathrm{c}$; ) $\mathrm{t}=180 \mathrm{c}$ 
и плотности их распределения. Предполагая, что исследуемая поверхность является фрактальным объектом, для определения значения фрактальной размерности применялся метод кубов. Для анализа структуры поверхности использовалась программа для обработки изображений Gwyddion, позволяющая получить значение фрактальной размерности исследуемой поверхности шлифа желчного камня. В качестве метода определения значения фрактальной размерности применялся метод кубов. Алгоритм основан на наложении кубической решетки с постоянной $l$ (стороной ячейки) на поверхность, растянутую по $z$. Производится подсчет кубов $N(l)$, которые включают хотя бы один пиксель изображения. На каждом шаге постоянная $l$ уменьшается вдвое до тех пор, пока $l$ не становится равным расстоянию между двумя соседними пикселями. Наклон графика $\log N(l)$ от $\log 1 / l$ дает значение фрактальной размерности $D$.

Фрактальная размерность поверхности слоистого желчного камня до воздействия лазерного излу-

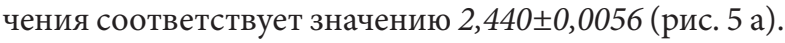

Для радиально-лучистого камня значение фрактальной размерности $-2,517 \pm 0,0056$ (рис. 5 б).

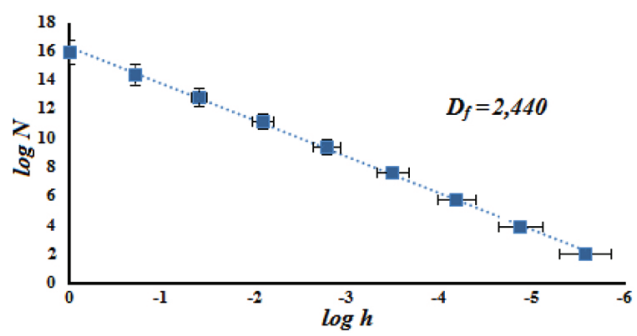

a)

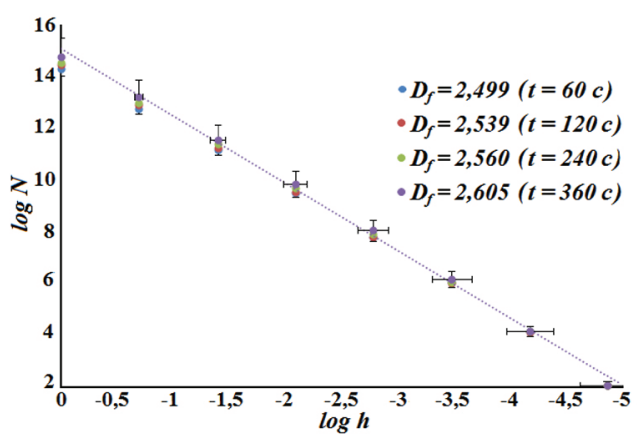

B)
На рисунке 5 в представлены графики зависимости $\log N$ от $\log h$ (где $l-$ постоянная кубической решетки, $N$ - количество кубов, включающих хотя бы один пиксель изображения, $h=1 / l-$ размер элементарной фигуры) для различного времени воздействия лазерного излучения на слоистый желчный камень. По данной зависимости видно, что при увеличении времени воздействия полупроводниковым лазером на слоистый желчный камень происходит незначительное увеличение фрактальной размерности. С учетом погрешности все значения лежат в доверительном интервале. Увеличение фрактальной размерности связано с тем, что при облучении слоистого камня формируются вторичные структуры, которые при увеличении времени воздействия увеличиваются в своем размере, что подтверждается фотографиями поверхности. Что касается радиально-лучистого желчного камня, то при сравнении фрактальной размерности мы видим, что при увеличении времени воздействия полупроводниковым лазером она незначительно уменьшается (рис. 5 г). Можно предположить, что это связано с тем, что радиально-лучистый желчный камень, в отличие от слоистого, не разрушается, а плавится. Следовательно, в результате плавления средние размеры кристаллитов уменьшаются.

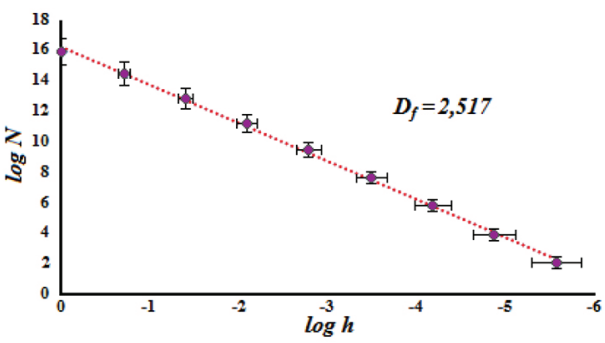

б)

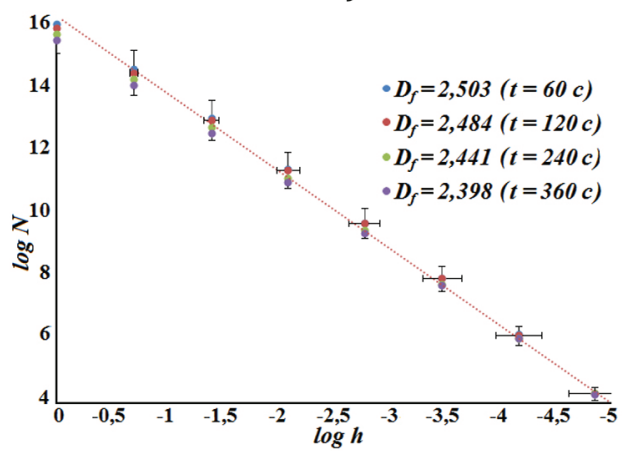

г)

Рис. 5. Зависимость $\log (N(l))$ от $\log (\mathrm{h})$ для поверхности шлифа: a) слоистого желчного камня до воздействия лазерного излучения; б) радиально-лучистого желчного камня до воздействия лазерного излучения; в) слоистого желчного камня после воздействия лазером, $\lambda=405 \mathrm{HM}, I=6,35 \cdot 10^{5} \mathrm{~B}{ }^{2} \mathrm{~m}^{2} ;$ г) радиально-лучистого желчного камня после воздействия лазером, $\lambda=405 \mathrm{Hм}, I=6,35 \cdot 10^{5} \mathrm{BT} / \mathrm{M}^{2}$

На рисунке 6 представлены характерные структуры, образованные вторичными частицами под воздействием лазерного излучения на шлиф слоистого желчного камня. Вторичные частицы получены в ре- зультате абляции, т.е. в процессе уноса вещества с поверхности шлифа желчного камня под воздействием излучения и обтекающего горячего парогазового потока. Их осаждение происходило на стеклянную под- 
ложку, расположенную на расстоянии 5-15 мм от области воздействия лазерного излучения. Структуры вторичных частиц белого цвета представляют собой скопления одиночных частиц-элементов, имеющих форму, близкую к сферической. Средний размер данных частиц порядка 186 нм.
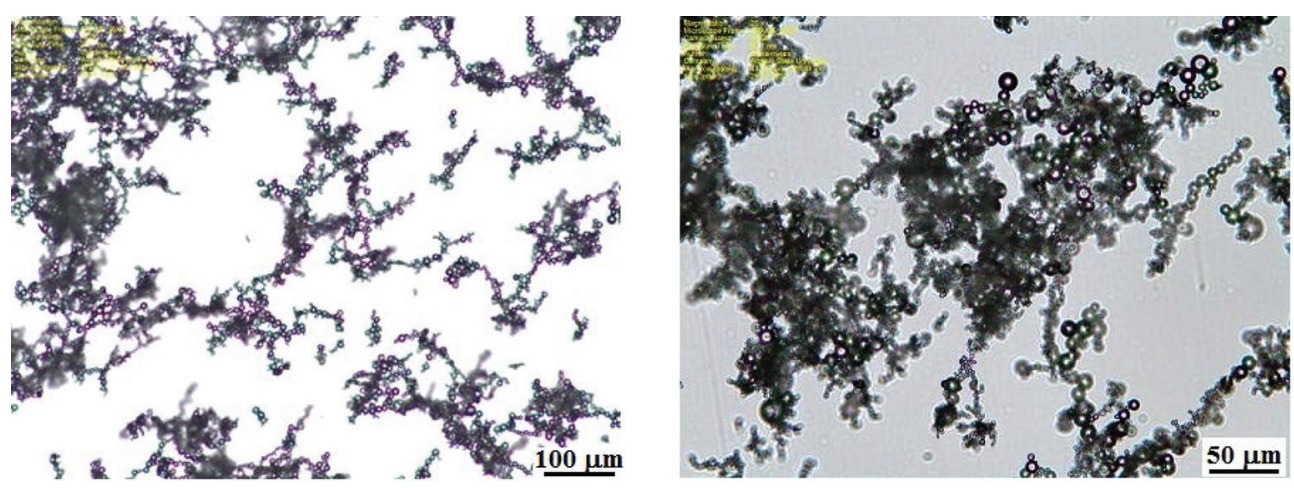

Рис. 6. Вторичные частицы, образующиеся при воздействии лазерного излучения на слоистый желчный камень, $\lambda=1064$ нм, $\mathrm{I}=25 \cdot 10^{6} \mathrm{~B}$ т $/ \mathrm{M}^{2}$

\section{Заключение}

Проведены исследования структуры поверхности шлифов желчных камней, рассчитана их фрактальная размерность и исследованы структурные изменения, происходящие при воздействии лазерного излучения на желчные камни. Анализ морфологической картины структурных изменений поверхности биоминеральных образований после воздействия лазерного излучения включал определение следующих структурных параметров: целостность контуров зоны облучения, наличие разрушения структуры.

При расчете фрактальной размерности поверхности образцов установлено, что под воздействием лазерного излучения на слоистые желчные камни ее значение увеличивается, а на радиально-лучистые, наоборот, убывает.

Скопления игольчатых кристаллов, в виде которых кристаллизуется холестерин, и их фрагменты, отрывающиеся от желчного камня в процессе его разрушения лазерным излучением, могут разноситься желчью и полностью не выводиться из желчного пузыря или холедоха, травмируя стенки органа, а образовавшиеся вторичные частицы - способствовать закупорке желчных протоков. Во время литотрипсии образуется мутная взвесь и теряется четкий визуальный контроль. Рецидив после дробления камней возникает с вероятностью от 30 до $50 \%$ всех случаев $[14$, c. $73-75]$.

\section{Библиографический список}

1. Новикова Е.А., Малов А.Н., Вайчас А.А., Камышев И.А. О возможности лазерного управления процессами роста желчных камней // XII Всеросс. молодежный Самарский конкурс-конфер. научн. работ по оптике и лазерной физике : сборник конкурсных докладов. М., 2014;

2. Хрячков В.В., Левченко Н.В., Белоусов В.В. Прицельная контактная лазерная литотрипсия: новые возможности в лечении желчнокаменной болезни // Успехи современного естествознания. 2008. № 5.

3. Боровкова Е.В. Морфологические типы желчных камней // Вестник ин-та геологии. 2004. № 5.

4. Асланов А.М., Яловега Г.Э., Колмакова Т.С., Бржезинская М.М. Микроэлементный состав и ультраструктура желчных камней разного типа // Современные проблемы науки и образования. 2015. № 3.
5. Поляков В.В., Устинов Г.Г., Петрухно Е.В Исследование элементного состава и структуры желчных камней с помощью растровой электронной микроскопии // Медицинская физика. 2010. № 4 (48).

6. Поляков В.В., Устинов Г.Г., Петрухно Е.В. Применение многомерного анализа данных к исследованию физико-механических характеристик биоминеральных образований // Биомедицинская радиоэлектроника. 2011. № 12.

7. Устинов Г.Г., Поляков В.В. Структура и физико-механические свойства желчных камней : монография. Барнаул, 2014.

8. Суворова Е.И., Пантюшев В.В., Волошин А.Э. Методы анализа химического и фазового состава желчных камней // Кристаллография. 2017. Т. 62. № 6.

9. Размахнин Е.В., Коновалова О.Г. Особенности минерального состава желчных конкрементов при изучении 
спектров испускания свободных атомов и ионов в газовой фазе // Забайкальский мед. вестник. 2015. № 2.

10. Gondal M.A., Shemis M.A., Khalil A.A.I., Nasr M.M. Gondal B. Laser produced plasma diagnosis of carcinogenic heavy metals in gallstones. // JAAS: Journal of Analytical Atomic Spectrometry. 2016. V. 31. № 2.

11. Singh V.K., Rai A.K., Singh V., Thakur S.N., Rai P.K., Singh J.P. Quantitative analysis of gallstones using laser-induced breakdown spectroscopy. // Applied Optics. 2008. V. 47. № 31.

12. Машина Е.В., Пискунова Н.Н., Асхабов А.М., Макеев Б.А. Механизм роста кристаллов моногидрата холесте- рина в холелитах // Записки Российского минералогич. обва. 2015. Т. 144. № 5.

13. Франке В.Д., Гликин А.Э., Котельникова Е.Н., Плоткина Ю.В., Шугаев А.И., Козлов А.В., Салихов И.Н. Биоминералогия и кристаллогенезис желчных камней // Записки Российского минералогич. об-ва. 2008. Т. 137. № 5.

14. Агзамов Р.Ш., Трифонова Э.В. Дробление камней в желчном пузыре: непосредственные и отдаленные результаты // Сибирский мед. журнал. 2012. Т. 108. № 1. 